\title{
Promoting Mental Wellbeing and Social Inclusion through Art: Six Month Follow-up Results from Open Arts Essex
}

\author{
Ceri Wilson a, Jenny Secker ${ }^{\mathrm{a}}$, Lyn Kent ${ }^{\mathrm{a}}$, Jo Keay ${ }^{\mathrm{b}}$ \\ ${ }^{a}$ Faculty of Health, Social Care and Education, Anglia Ruskin University, Chelmsford, \\ Essex, UK \\ ${ }^{b}$ Open Arts, Hadleigh, Essex, UK
}

Dr Ceri Wilson* (corresponding author), Senior Research Fellow, Anglia Ruskin University, Faculty of Health, Social Care and Education, Bishop Hall Lane, Chelmsford, Essex, CM11SQ, UK, ceri.wilson@anglia.ac.uk, 08451964189

Dr Jenny Secker, Emeritus Professor of Mental Health, Anglia Ruskin University, Faculty of Health, Social Care and Education, Bishop Hall Lane, Chelmsford, Essex, CM11SQ, UK, jenny.secker@anglia.ac.uk

Lyn Kent, Service User Researcher, formerly South Essex Service User Research Group (SE-SURG) Researcher/Administrator, Anglia Ruskin University, Faculty of Health, Social Care and Education, Bishop Hall Lane, Chelmsford, Essex, CM11SQ, UK, lynjkent@gmail.com

Jo Keay, Open Arts Manager, Open Arts, The Art House next to Hadleigh Old Fire Station, 19 High Street, Hadleigh, Essex SS7 2PA, UK, Jo.Keay@sept.nhs.uk

Acknowledgements

1. This work was supported by the Big Lottery under grant number PID 10255592. 


\section{Promoting Mental Wellbeing and Social Inclusion through Art: Six Month Follow-up Results from Open Arts Essex}

Previous evaluations have demonstrated improvements in wellbeing and social inclusion for people with mental health difficulties after participating in Open Arts' introductory participatory arts courses. This evaluation aimed to ascertain whether improvements are maintained long-term. Course participants completed measures of wellbeing and social inclusion at the beginning and end of their course and after three and six months. At initial follow-up participants rated their experience of their course, and at three and six months they reported activities taken up after attending. Scores significantly increased from baseline to first follow-up and remained significantly higher than at baseline at three and six months. End-of-course ratings were positive and most participants continued their art work. Other activities included education/training and voluntary/paid work. Further studies are needed to examine whether improvements can be attributed with confidence to arts participation, but these results add to a growing weight of evidence pointing to that conclusion.

Keywords: arts activities, participatory arts; mental health; mental wellbeing, social inclusion; six month follow-up

\section{Background}

Open Arts Essex was established by the South Essex Partnership University NHS Foundation Trust in 2008 with the aim of promoting mental wellbeing and social inclusion for people experiencing or at risk of mental health problems in South Essex, England. The core activity of the project is the provision of introductory 12-week art courses in community venues. Course participants include mental health service users, carers and individuals who self-refer, and the courses draw on art therapy principles relating to the therapeutic experience of art-making with a group (Wood, 2000) and facilitated learning (Rogers \& Freiberg 1993). 
Improving wellbeing and social inclusion are key strands of current mental health policy in England (Her Majesty’s Government, 2011) and the potential of arts participation in this respect has been of increasing, if somewhat fluctuating, interest (Clift et al., 2009). In recent years, for example, reports from both Arts Council England (2014) and the Arts and Humanities Research Council (Crossick \& Kaszynska, 2016) highlight health and wellbeing as one area in which arts and culture can make a valuable contribution. In 2004 an influential UK cross-governmental report also highlighted arts participation as a potential means of addressing high levels of social exclusion amongst people experiencing mental health problems (Office of the Deputy Prime Minister, 2004).

Although data to support the mental health and wellbeing benefits of arts participation has been accumulating for more than two decades (White, 2016), with evidence for social inclusion benefits also emerging (Hacking et al., 2008), reviews have consistently concluded that a stronger body of evidence is required (Angus 2002; Clift et al., 2009; Jermyn, 2004; Staricoff, 2004; Wreford, 2010). Evaluation was therefore built into Open Arts’ provision from the outset, with the aim of contributing to the evidence base as well as supporting the project's own funding applications.

Initial evaluations of the introductory courses demonstrated significant improvements in mental wellbeing and social inclusion (Secker et al. 2011), including in comparison with a waiting list control group (Margrove et al. 2013). However, neither study was able to follow-up participants beyond the end of their course and both identified longer-term follow-up as an essential step in further developing the evidence base. This remains rare, although Stickley (2010) was able to follow up 11 participants over a period of 18 months using narrative methods to explore stories of involvement with a community arts programme promoting mental health. He concludes that 
involvement in community arts activities may help to resolve people’s need for individual and social identity and that this, in turn, may assist people to find a sense of social and thus personal belonging.

In 2013 an opportunity to contribute further to the goal of longer-term follow-up arose when Open Arts, now hosted within the charitable funds managed by the South Essex Partnership University NHS Foundation Trust, was awarded funding by the UK's Big Lottery to provide ten introductory arts courses. The courses were delivered over two years in localities across South Essex. They included eight visual arts courses comprising 12 two-hour weekly sessions, a drama course also comprising 12 two-hour weekly sessions and a six-week percussion course, again with a two-hour session each week.

This article presents a service evaluation of these ten introductory participatory arts courses, providing the first long-term follow-up (at three and six months) of Open Arts programmes. As a service evaluation the study did not need UK National Health Service (NHS) ethics approval and approval was therefore sought and obtained from the South Essex Partnership University NHS Foundation Trust’s Research Governance Group to carry out the study as an evaluation.

\section{Methods}

Course participants were invited to complete questionnaires including measures of mental wellbeing and social inclusion at the beginning and end of their course. Further questionnaires were then mailed to participants three months after the end of their course and again after six months. The measures used were the Warwick-Edinburgh Mental Wellbeing Scale (WEMWBS: Tennant et al., 2007) and a short version of the Social Inclusion Scale (SIS: Secker et al., 2009) comprising subscales measuring social 
isolation, social acceptance and social relations. Demographic information (gender, age and ethnicity) was requested on the first questionnaire. At the end of their course, participants were asked to rate their experience of their course in terms of enjoyment, development of skills and confidence, motivation, feeling more positive and relationships with other people. At the three and six month follow-ups they were asked to select any activities they had taken up as a result of attending their Open Arts course from a multiple choice list and to write in any others not included in the list.

\section{Measures}

The Warwick-Edinburgh Mental Wellbeing Scale (WEMWBS; Tennant et al. 2007)

The WEMWBS measures positive affect, psychological functioning and interpersonal relationships. A measure of mental well-being was chosen in order to correspond with the ethos of participatory arts and health projects (White 2009) and the increasing emphasis in health policy on promoting positive mental health (Her Majesty’s Government 2011). The WEMWBS consists of fourteen positively phrased statements (e.g. 'I’ve been feeling optimistic about the future', 'I've been feeling useful', 'I've been feeling confident') rated on Likert scales: 'None of the time', 'Rarely', 'Some of the time', 'Often' and 'All of the time'. The overall score is the sum of each item with a higher score reflecting higher mental well-being. This scale has demonstrated high internal consistency, construct validity, discriminant validity and test-retest reliability (e.g. Bartram et al. 2011; Clarke et al. 2011; Tennant et al. 2007). 
The Social Inclusion Scale (SIS; Secker et al. 2009)

The original SIS consisted of 22 items and three subscales: social isolation, social relations and social acceptance. This measure has demonstrated good internal consistency and concurrent validity (Secker et al. 2009). The shortened version (twelve items) used in the present evaluation has also demonstrated good internal consistency (Margrove et al. 2013). The scale consists of statements (e.g. 'I have friends I see or talk to every week', 'I have felt accepted by my family', 'I have felt that I am playing a useful part in society') in which participants choose the option on a Likert scale ('Not at all', 'Not particularly', 'Yes a bit' and 'Yes definitely') that best describes their relationships with other people over the last month. The overall score is the sum of each item; the score of each subscale is the sum of items in that subscale.

\section{Analysis}

Scores on both measures and on the SIS subscales were normally distributed, therefore paired t-tests were used to compare scores between baseline and each of the three follow-ups. Scores were also compared between first follow-up and three month followup, between first follow-up and six month follow-up and between the three and six month follow-ups. These analyses were repeated with carers and participants from the shorter percussion group removed to check whether results from these distinct groups impacted on the overall results. There was no significant impact and results for all responding participants are therefore reported. 


\section{Results}

\section{Participants}

A total of 106 participants completed questionnaires at baseline, 77 completed questionnaires at initial follow-up, 30 completed questionnaires at three month followup and 39 completed questionnaires at six month follow-up (however data from one participant was removed at six month follow-up as the same response was given to each question and was deemed unreliable). Participants included in the different stages of analysis comprised 74 participants who completed measures at both baseline and initial follow-up, 29 participants who completed measures at both baseline and three month follow-up, 38 who completed measures at both baseline and six month follow-up, 26 participants who completed measures at both initial follow-up and three month followup, 37 participants who completed measures at both initial and six month follow-up, and 14 participants who completed measures at both three and six month follow-up. Demographic data provided by participants at baseline indicated that around three quarters (72.5\%) were female. Two thirds (66.1\%) were in their middle years (aged 40 to 65), with a further fifth (18.4\%) aged between 30 and 39. The majority (93\%) were of White British ethnicity. These proportions did not change substantially at any of the follow-up periods. Numbers in the other age groups were considerably lower. At baseline, two participants aged 16 to 19, nine aged 20 to 29 and six aged over 65 returned questionnaires. Ethnic groups other than White British represented at baseline included two White Irish and two Other White participants, along with one person each describing themselves as Asian British, Chinese or of Mixed ethnicity. 


\section{Mental Wellbeing}

Participants’ mental wellbeing significantly increased from baseline $(M=23.61$, $S D=10.15)$ to first follow-up $(M=32.55, S D=10.78): t(73)=7.65, p<.001$. In order to assess whether this increase was maintained at three month follow-up a paired t-test was used to compare scores at first follow-up and three month follow-up. Scores at these time points did not significantly differ: $t(25)=.96, p=.344$. However, scores at six month follow-up were significantly lower than the first follow-up scores, decreasing from a mean of 34.62 to a mean of 29.00: $t(36)=4.17, p<.001$. The decrease from three month to six month follow-up was not significant: $t(13)=1.96, p=.072$.

Further paired t-tests revealed a significant increase from baseline to three month follow-up: $t(28)=3.77, p=.001$, and a significant increase from baseline to six month follow-up: $t(37)=2.85, p=.007$. See Table 1 for the mean difference in WEMWBS scores between each time point and Table 2 for mean scores at each time point.

\section{[INSERT TABLES 1 AND 2 ABOUT HERE]}

\section{Social Inclusion}

Participants' social inclusion scores significantly increased from baseline $(M=29.65$, $S D=7.38)$ to first follow-up $(M=34.19, S D=7.38): t(73)=5.73, p<.001$. Scores also significantly increased on all three subscales (see Table 3). 
Scores did not significantly differ between first follow-up and three month follow-up ( $p>.05$ ) however scores at six month follow-up were significantly lower than at first follow-up: $t(36)=2.32, p=.026$. Scores on the individual subscales did not significantly differ between first follow-up and either three or six month follow-up (all $p>.05)$. There was however a significant difference between three and six month followup scores: $t(13)=2.31, p=.038$.

Further paired t-tests revealed a significant increase from baseline to three month follow-up: $t(28)=3.48, p=.002$, and a significant increase from baseline to six month follow-up: $t(37)=2.38, p=.023$. See Table 4 for the mean difference in SIS scores between each time point and Table 5 for mean scores at each time point.

\section{[INSERT TABLES 4 AND 5 ABOUT HERE]}

\section{End of Course Evaluations}

Table 6 shows responses to the questions included in the first follow-up survey. Most notably all respondents reported enjoying their course and over $90 \%$ reported increased motivation to do art work and other activities. Over $80 \%$ also reported improved confidence, feeling more positive about things, and improved relationships as a result of participation. 


\section{Activities taken up as a Result of Course Participation}

Twenty-six participants responded to the multiple choice question about the activities they had taken up at the three month follow-up and 37 responded at six months. Taken together, their responses indicate that continuing with art work was the most common activity at both follow-ups. At three months, 16 of the 26 respondents were continuing their art work on their own and nine were continuing with friends or family. In addition seven were attending other art groups. At six months, 26 of the 37 respondents were continuing art on their own and ten with family or friends. Ten were attending other art groups and two had started an arts course at college. At each time point only five participants indicated that they had not continued their art work.

At the three month follow-up three participants responded to the opportunity to write in any other activities they had taken up. Twenty-six responded at six months and nine responded at both follow-ups. At three months, two had taken up voluntary work and the third had obtained paid work as a gardener alongside studying for a National Vocational Qualification in horticulture. In addition one participant had obtained paid employment at the Royal Opera House’s learning and participation centre in Thurrock 'my dream job’. At six months, five had taken up voluntary work and a further three intended to do so. Six participants had taken or were taking courses of study, while two others were hoping to start college courses in the future. Further activities added by participants at six months included joining a choir, running an art group at a local substance misuse service, organising a craft stall with a friend and making a documentary film relating to local history. In addition, two participants who had completed the drama course were involved in setting up an independent drama group. 
For all but one of the nine participants who responded at both follow-ups a clear picture emerged of progression on their chosen path. In one case a participant who had been involved in setting up an independent drama group at three months had taken on further voluntary roles at six months, including helping with an art class at a local Recovery College and mentoring student mental health nurses participating in a Buddy Scheme. Two other participants who had taken up voluntary work at three months had continued this at six months. One had also taken a number of Mental Health First Aid courses and had embarked on an Access to Health Professions course.

Where paid work was concerned, the participant who had obtained a gardening job at three months and was working towards a National Vocational Qualification in horticulture had progressed to a Higher National Diploma in horticulture at six months. The participant who had obtained work with the Royal Opera House at the three month follow-up was still in the job and described how she was assisting with developing

cultural experience opportunities for children and young people. A third participant had been involved in a photography project at three months and at six months was working as a complementary therapist.

For two participants, increased social activity was the predominant theme. At three months one of the two had been doing crafts with a group of friends and was also learning to knit. At six months she was continuing her craft work and was now knitting regularly with a neighbour. The other participant had joined a carers' social group at three months and at six months was looking for another course or group to join.

\section{Discussion}

The results of this six month follow-up study of participatory arts courses add further weight to the growing evidence that arts participation is an effective means of 
promoting mental wellbeing and social inclusion for people experiencing or at risk of mental health problems. This represents the first long-term follow-up of Open Arts participatory arts interventions. As in previous evaluations (Margrove et al., 2013; Secker et al., 2011), both mental wellbeing and social inclusion scores had increased significantly by the end of course follow-up. Attribution of these improvements to Open Arts is supported by the high proportions of participants who rated their experience of Open Arts positively in relation to factors associated with mental wellbeing and social inclusion. Over 90\% rated their motivation to do art work and other activities positively and over $80 \%$ reported improvements in confidence, feeling positive and relationships with others.

A further aim of this evaluation was to assess whether the benefits previously documented were maintained in the longer-term. The results show that the improvements were maintained three months after the end of the introductory courses on both measures. At six months scores had decreased since the three month follow-up but remained significantly higher than at baseline. Limited resources meant it was not possible to establish a control group with which to compare these results for course participants (with there being great difficulty in obtaining funding to cover the inclusion of a control group in such evaluations), and it therefore remains the case that they cannot be attributed to arts participation with complete confidence. However, participants' responses at follow-up to questions about activities they had taken up as a result of their course do suggest a positive impact. The majority were continuing their art work, and in light of the end of course results this in itself would be expected to help maintain the gains made during the courses. For those pursuing related courses of study or voluntary and paid work further social inclusion gains are likely as both education and employment are widely regarded as key indicators of inclusion (Levitas, 2006). The 
evidence of progression amongst participants who responded at both three and six months is particularly noteworthy in this respect. Taken together, then, the results of the evaluation give a promising indication of longer-term benefits that merits further investigation.

Whilst data to support the mental health, wellbeing and social inclusion benefits of arts participation has been accumulating (both in relation to Open Arts and other arts programmes) studies have rarely had the resources to follow-up long-term or to include a control group. The added evidence from this evaluation regarding the long-term benefits of arts participation marks an essential step in further developing the evidence base in the field; however, studies higher up the hierarchy of evidence represents the next step for building the evidence base going forward (for example, through the implementation of a Randomised Controlled Trial to evaluate the impact of arts participation on mental wellbeing and social inclusion).

\section{Conclusions}

The first long-term follow-up evaluation of Open Arts has shown that participation in Open Arts introductory courses was associated with significant improvements in mental wellbeing and social inclusion by the end of the introductory courses and that the improvements were maintained in the longer-term. Although scores decreased between the three and six month follow-ups the improvement from baseline scores remained significant. Further studies are needed to examine whether these results can be attributed with confidence to arts participation, but taken together with participants' reports of activities taken up as a result of attending their course the results do add to a growing weight of evidence pointing to that conclusion. 
Word count: 3144 (including abstract)

\section{References}

Angus, J. (2002) A review of evaluation in community-based art for health activity in the UK. London: Health Development Agency.

Arts Council England. (2014). The value of arts and culture to people and society. Manchester: Arts Council England.

Bartram, D. J., Yadegarfer, G., Sinclair, J. M. A. \& Baldwin, D. S. (2011). Validation of the Warwick-Edinburgh Mental Well-being Scale (WEMWBS) as an overall indicator of population mental health and well-being in the UK veterinary profession. The Veterinary Journal, 187, 397-98. doi:10.1016/j.tvjl.2010.02.010

Clarke, A., Friede, T., Putz, R., Ashdown, J., Martin, S., Blake, A., Adi, Y., Parkinson, J., Flynn, P., Platt, S. \& Stewart-Brown, S. (2011). Warwick-Edinburgh Mental Well-being Scale (WEMWBS): Validated for teenage school students in England and Scotland. A mixed methods assessment. BMC Public Health, 11, 487-95. doi:10.1186/1471-2458-11-487

Clift, S., Camic, P., Chapman, B., Clayton, G., Daykin, N., Eades, G., Parkinson, C., Secker, J., Stickley, Y. \& White, M. (2009). The state of arts and health in England. Arts \& Health: An International Journal for Research, Policy and Practice, 1, 6-35. doi:10.1080/17533010802528017

Crossick, G. \& Kaszynska, P. (2016) Understanding the value of arts and culture. The AHRC Cultural Value Project. Swindon: Arts and Humanities Research Council. 
Hacking, S., Secker, J., Spandler, H., Kent, L. \& Shenton, J. (2008). Evaluating the impact of participatory art projects for people with mental health needs. Health and Social Care in the Community, 16, 638-48. doi: 10.1111/j.13652524.2008.00789

Her Majesty’s Government. (2011). No health without mental health. A crossgovernment mental health outcomes strategy for people of all ages. London: Department of Health.

Jermyn, H. (2004). The art of inclusion. Research report 35. London: Arts Council England.

Levitas, R. (2006). The concept and measurement of social exclusion. In C. Pantazis, D. Cordon and R. Levitas (eds.) Poverty and Social Exclusion in Britain: The Millennium Survey, pp.123-162. Bristol: The Policy Press.

Margrove, K., SE-SURG., Heydinrych, K. \& Secker, J. (2013). Waiting list controlled evaluation of a participatory arts course for people experiencing mental health problems. Perspectives in Public Health, 133, 28-35. doi:10.1177/1757913912461587

Office of the Deputy Prime Minister. (2004). Mental health and social inclusion. London: Office of the Deputy Prime Minister.

Rogers, C. \& Freiberg, H. (1993). Freedom to Learn, 3rd ed., New York: Merrill. Secker, J., Hacking, S., Kent, L., Shenton, J., \& Spandler, H. (2009). Development of a measure of social inclusion for arts and mental health project participants. Journal of Mental Health, 18, 65-72. doi: 10.1080/09638230701677803

Secker, J, Loughran, M , Heydinrych, K. \& Kent, L. (2011). Promoting mental wellbeing and social inclusion through art: evaluation of an arts and mental health project. Arts \& Health: An International Journal for Research, Policy and 
Practice, 3, 51-60. doi: 10.1080/17533015.2010.541267

Staricoff, R. (2004). Arts in health: a review of the medical literature. London: Arts Council England.

Stickley T. (2010). The arts, identity and belonging: a longitudinal study. Arts \& Health: An International Journal for Research, Policy and Practice, 2, 23-32. doi: $10.1080 / 17533010903031614$

Tennant, R., Hiller, L., Fishwick, R., Platt, S., Joseph, S., Weich, S., Parkinson, J., Secker, J., \& Stewart-Brown, S. (2007). The Warwick-Edinburgh Mental Wellbeing Scale (WEMWBS): development and UK validation. Health and Quality of Life Outcomes, 5, 63. doi: 10.1186/1477-7525-5-63

White, M. (2009). What the experts think. In P. Duval (ed.) Restoring the Balance: The Effect of Arts Participation on Well-Being and Health, pp.20-23. Newcastle upon Tyne: Voluntary Arts England.

White, M. (2016). The means to flourish: arts in community health and education. In S. Clift and P. Camic (eds.) Oxford textbook of creative arts, health and wellbeing. International perspectives on policy, practice and research, pp.41-48. Oxford: Oxford University Press.

Wood, C. (2000). The significance of studios. Inscape, 5, 40-53. doi:10.1080/17454830008413089

Wreford, G. (2010). The state of arts and health in Australia. Arts \& Health: An International Journal for Research, Policy and Practice, 2, 8-22. doi:10.1080/17533010903421484 
Table 1. Mean difference in WEMWBS scores in time point comparisons.

\begin{tabular}{|c|c|c|c|c|}
\hline Time point & $n$ & $\begin{array}{l}\text { Mean } \\
\text { difference }\end{array}$ & $t$ & $p$ \\
\hline $\begin{array}{l}\text { Baseline and initial } \\
\text { follow-up }\end{array}$ & 74 & +8.94 & 7.65 & $<.001 *$ \\
\hline $\begin{array}{l}\text { Baseline and } 3 \\
\text { months }\end{array}$ & 29 & +6.07 & 3.77 & $.001 *$ \\
\hline $\begin{array}{l}\text { Baseline and } 6 \\
\text { months }\end{array}$ & 38 & +4.11 & 2.85 & $.007 *$ \\
\hline $\begin{array}{l}\text { Initial follow-up } \\
\text { and } 3 \text { months }\end{array}$ & 26 & -1.73 & .96 & .34 \\
\hline $\begin{array}{l}\text { First follow-up and } \\
6 \text { months }\end{array}$ & 37 & -5.62 & 4.17 & $<.001^{*}$ \\
\hline $\begin{array}{l}3 \text { months and } 6 \\
\text { months }\end{array}$ & 14 & -3.71 & 1.96 & .072 \\
\hline
\end{tabular}

${ }^{*} p<.05$ 
Table 2. Mean WEMWBS scores at each time point.

\begin{tabular}{|c|c|c|c|}
\hline & & Mean & SD \\
\hline \multirow[t]{2}{*}{ Pair $1(n=74)$} & Baseline & 23.61 & 10.15 \\
\hline & Initial follow-up & 32.55 & 10.78 \\
\hline \multirow[t]{2}{*}{ Pair $2(n=29)$} & Baseline & 25.03 & 10.77 \\
\hline & 3 months & 31.10 & 10.12 \\
\hline \multirow[t]{2}{*}{ Pair $3(n=38)$} & Baseline & 24.18 & 11.13 \\
\hline & 6 months & 28.29 & 13.63 \\
\hline \multirow[t]{2}{*}{ Pair $4(n=26)$} & Initial follow-up & 33.77 & 10.16 \\
\hline & 3 months & 32.04 & 10.28 \\
\hline \multirow[t]{2}{*}{ Pair $5(n=37)$} & Initial follow-up & 34.62 & 12.04 \\
\hline & 6 months & 29.00 & 13.09 \\
\hline \multirow[t]{2}{*}{ Pair $6(n=14)$} & 3 months & 33.00 & 10.55 \\
\hline & 6 months & 29.29 & 13.50 \\
\hline
\end{tabular}


Table 3. Baseline and follow-up scores on each subscale of the SIS.

\begin{tabular}{lllll}
\hline SIS Subscale & $\begin{array}{l}\text { Mean baseline } \\
\text { score (SD) }\end{array}$ & $\begin{array}{l}\text { Mean follow-up } \\
\text { score (SD) }\end{array}$ & $\boldsymbol{p}$ \\
\hline Social Isolation & $10.15(3.09)$ & $11.70(3.00)$ & 5.01 & $<.001^{*}$ \\
Social Acceptance & $13.46(3.16)$ & $14.63(3.38)$ & 3.88 & $<.001^{*}$ \\
Social Relations & $10.06(3.60)$ & $13.53(3.45)$ & 5.67 & $<.001^{*}$ \\
SIS Total & $29.65(7.38)$ & $34.19(7.38)$ & 5.73 & $<.001^{*}$ \\
\hline${ }^{*} p<.05$ & & & &
\end{tabular}


Table 4. Mean difference in overall SIS scores in time point comparisons.

\begin{tabular}{|c|c|c|c|c|}
\hline Time point & $n$ & $\begin{array}{l}\text { Mean } \\
\text { difference }\end{array}$ & $t$ & $p$ \\
\hline $\begin{array}{l}\text { Baseline and initial } \\
\text { follow-up }\end{array}$ & 74 & +4.54 & 5.73 & $<.001 *$ \\
\hline $\begin{array}{l}\text { Baseline and } 3 \\
\text { months }\end{array}$ & 29 & +4.24 & 3.48 & $.002 *$ \\
\hline $\begin{array}{l}\text { Baseline and } 6 \\
\text { months }\end{array}$ & 38 & +2.97 & 2.38 & $.023 *$ \\
\hline $\begin{array}{l}\text { Initial follow-up } \\
\text { and } 3 \text { months }\end{array}$ & 26 & -.27 & .24 & .81 \\
\hline $\begin{array}{l}\text { Initial follow-up } \\
\text { and } 6 \text { months }\end{array}$ & 37 & -2.32 & 2.32 & $.026^{*}$ \\
\hline $\begin{array}{l}3 \text { months and } 6 \\
\text { months }\end{array}$ & 14 & -1.79 & 2.31 & $.038^{*}$ \\
\hline
\end{tabular}

${ }^{*} p<.05$ 
Table 5. Mean SIS scores at each time point.

\begin{tabular}{|c|c|c|c|}
\hline & & Mean & SD \\
\hline \multirow[t]{2}{*}{ Pair $1(n=74)$} & Baseline & 29.65 & 7.38 \\
\hline & Initial follow-up & 34.19 & 7.38 \\
\hline \multirow[t]{2}{*}{ Pair 2 (n=29) } & Baseline & 30.52 & 8.08 \\
\hline & 3 months & 34.76 & 7.30 \\
\hline \multirow[t]{2}{*}{ Pair $3(n=38)$} & Baseline & 30.42 & 7.24 \\
\hline & 6 months & 33.39 & 9.72 \\
\hline \multirow[t]{2}{*}{ Pair $4(n=26)$} & Initial follow-up & 35.23 & 6.95 \\
\hline & 3 months & 34.96 & 7.68 \\
\hline \multirow[t]{2}{*}{ Pair $5(n=37)$} & Initial follow-up & 36.22 & 7.66 \\
\hline & 6 months & 33.89 & 9.35 \\
\hline \multirow[t]{2}{*}{ Pair $6(n=14)$} & 3 months & 36.43 & 8.10 \\
\hline & 6 months & 34.64 & 8.22 \\
\hline
\end{tabular}


Table 6. Responses to questions about the Open Arts course $(n=74)$.

\begin{tabular}{|c|c|c|c|c|c|}
\hline Question & $\begin{array}{l}\text { Missing } \\
\text { data }\end{array}$ & $\begin{array}{l}\text { Not at all } \\
\text { (0) }\end{array}$ & $\begin{array}{l}\text { No not much } \\
\text { (1) }\end{array}$ & $\begin{array}{l}\text { Yes a little } \\
\text { (2) }\end{array}$ & $\begin{array}{l}\text { Yes a lot } \\
\text { (3) }\end{array}$ \\
\hline & & Frequency (\%) & Frequency (\%) & Frequency (\%) & Frequency (\%) \\
\hline $\begin{array}{l}\text { Have you } \\
\text { enjoyed your } \\
\text { Open Arts } \\
\text { course? }\end{array}$ & 0 & - & - & $3(4.1 \%)$ & 71 (95.9\%) \\
\hline $\begin{array}{l}\text { Have your art } \\
\text { skills } \\
\text { developed? }\end{array}$ & 0 & - & $1(1.4 \%)$ & 25 (33.8\%) & 48 (64.9\%) \\
\hline $\begin{array}{l}\text { Has your } \\
\text { confidence } \\
\text { increased? }\end{array}$ & 1 & $1(1.4 \%)$ & 9 (12.3\%) & 27 (37\%) & 36 (49.3\%) \\
\hline $\begin{array}{l}\text { Has your } \\
\text { motivation to } \\
\text { do artwork } \\
\text { increased? }\end{array}$ & 0 & $1(1.4 \%)$ & $2(2.7 \%)$ & 22 (29.7\%) & 49 (66.2\%) \\
\hline $\begin{array}{l}\text { Has your } \\
\text { motivation to } \\
\text { do other things } \\
\text { increased? }\end{array}$ & 1 & $1(1.4 \%)$ & $6(8.2 \%)$ & 38 (52.1\%) & 28 (38.4\%) \\
\hline $\begin{array}{l}\text { Do you feel } \\
\text { more positive } \\
\text { about things? }\end{array}$ & 0 & $2(2.7 \%)$ & $8(10.8 \%)$ & 35 (47.3\%) & 29 (39.2\%) \\
\hline $\begin{array}{l}\text { Have your } \\
\text { relationships } \\
\text { with other } \\
\text { people } \\
\text { improved? }\end{array}$ & 0 & $2(2.7 \%)$ & 11 (14.9\%) & 38 (51.4\%) & 23 (31.1\%) \\
\hline
\end{tabular}

